\title{
APROPIACIÓN DEL ESPACIO URBANO EN ATLIXCO, PUEBLA. Muestra de los intangibles a través de sus manifestaciones simbólicas
}

\author{
Aurelia Flores Rodríguez \\ Eduardo Tototzintle Huitle \\ Benemérita Universidad Autónoma de Puebla \\ Dra. Leticia Villalobos Sampayo \\ aure.flores.arq@gmail.com
}

\section{RESUMEN}

Al realizar un estudio actual sobre el patrimonio de la ciudad de Atlixco, el presente trabajo mostrará la trascendencia que existe del patrimonio intangible de la región a raíz de la forma de apropiación de los lugares por medio de las personas que dejan huella en ellos. Estas formas de apropiación generan cambios a través de manifestaciones sociales, como fiestas patronales, y permiten otorgar un mayor valor de reconocimiento, en el que las transformaciones se analizan más allá del aspecto social, es decir, en un aspecto urbano como parte del contexto que rige y complementa el ambiente natural de los inmuebles históricos. Así es como además de conocer las costumbres y tradiciones se difunde su estudio por medio del vínculo entre los espacios que ocupan para desarrollarse y los cambios que generan al entorno, impactando no solo el paisaje urbano-arquitectónico sino la memoria individual y colectiva de la ciudad.

Palabras Clave: Patrimonio Intangible, Apropiación, Espacio Urbano-Arquitectónico

\begin{abstract}
When carrying out a current study on the heritage of the city of Atlixco, the present work will show the transcendence that exists of the intangible heritage of the region as a result of the way of appropriation of the places by means of the people who leave their mark on them. These forms of appropriation generate changes through social manifestations, such as patronal festivities, and allow the granting of a greater recognition value, in which transformations are analyzed beyond the social aspect, that is, in an urban aspect as part of the context governs and complements the natural environment of historic buildings. This is how in addition to knowing the customs and traditions, their study is disseminated through the link between the spaces they occupy to develop and the changes they generate in the environment, impacting not only the urbanarchitectural landscape but the individual and collective memory of the city .
\end{abstract}

Key Words: Heritage, Appropriation, Urban Space, Intangible 


\section{INTRODUCCIÓN}

En el presente trabajo se trata la importancia del uso del espacio público urbano en el rescate de las manifestaciones simbólicas como parte del patrimonio intangible de la ciudad de Atlixco, y como a lo largo de la historia no solo se han afianzado sino trascendido, gracias a la difusión de la sociedad, la cual ha empleado las manifestaciones para dar a conocer sus tradiciones y costumbres dentro y fuera de la región.

En principio este estudio complementa la información del trabajo de catálogo de monumentos que se realiza en la ciudad, el cual pretende incluir un apartado que valore el contexto urbano y las celebraciones en estos espacios en los que están inmersos los inmuebles. Además de ello hacer uso del registro de eventos que tras el trabajo se reconocen como medio para salvaguardar las tradiciones de la ciudad, las cuales se están olvidando, tras la condicionante de que no hay un registro documental y solo llegan a través de la tradición oral hasta las nuevas generaciones.

El presente trabajo se desarrolla en cuatro apartados en los cuales el primero da a conocer la historia de forma general del surgimiento de la ciudad, apartado en el cual se enuncia el origen, las formas de vida y cambios a nivel social, económico y cultural que generaron cambios a nivel territorial y constructivo de la ciudad. El segundo capítulo describe el centro que origino la ciudad, sus características y crecimiento a partir del mismo contexto urbano y el modo en que durante cada período se constituyo una forma de hacer arquitectura con sus variantes en lo religioso, civil y militar.

El tercer apartado trata el tema de la apropiación del espacio urbano, sus transformaciones y el vínculo creado con el patrimonio intangible para reforzar la memoria de la sociedad por medio de sus costumbres y celebraciones. Lo cual lleva a abordar la parte inmaterial del patrimonio cultural que poco se ha tratado y que ha permitido percibir al edificio en todo un contexto cultural de naturaleza, actores y valores más allá del aspecto material.

Culmina el trabajo con un último apartado que describe tres de las más importantes celebraciones a nivel local que han trascendido a nivel nacional y que han reforzado a la sociedad al ser partícipes y organizadores de lo que ya conocen. El impacto a nivel urbano de cada uno y los cambios en el entorno suscitados por estas prácticas, las cuales se hacen más numerosas cada año por la población foránea que participa. Así mismo se reconoce la importancia del patrimonio intangible de Atlixco para valorar su uso como medio de conocimiento cultural que refuerce las acciones sobre el territorio e inmuebles a favor de su preservación, considerando la repercusión a nivel urbano y social de las manifestaciones al hacer uso del espacio público de forma cotidiana.

\section{1 ÁMBITO HISTORICO-GEOGRÁFICO}

Atlixco se localiza en la Republica Mexicana en el Estado de Puebla, integrante de la Región $V$ en lo que fuera parte del poderío del territorio Puebla-Tlaxcala con una población de 127,062 habitantes y una extensión de 293.01 kilómetros cuadrados, según último censo de 2010 por INEGI (Instituto Nacional de Estadística, Geografía e Información); siendo el $0.85 \%$ del Estado, que lo ubica en el $51^{\circ}$ lugar con respecto a los demás municipios.

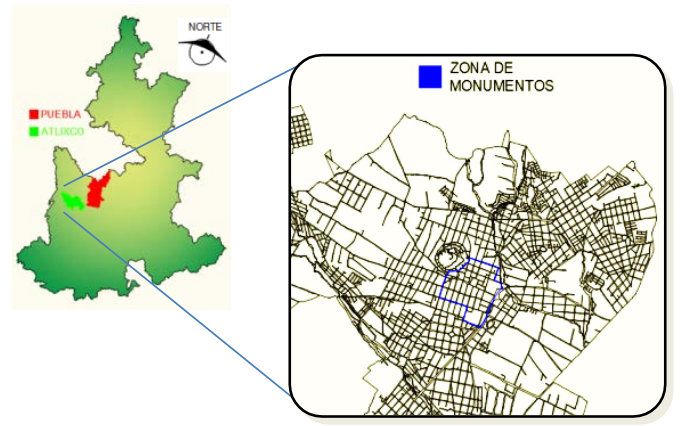

Localización de la Zona de estudio

(Elaboración propia a partir de datos cartográficos, 2018)

La historia de lo que hoy se conoce como ciudad, se remonta al primer asentamiento llamado Acapetlahuacan que significa "Lugar donde tienen esteras de caña", en torno a un manantial que hoy ha quedado lejos del 
actual centro. A la llegada de los españoles, se menciona; cierta división ya que Acapetlahuacan estaba en constantes riñas con los pueblos de Calpan y Huejotzingo, quienes finalmente se dividieron las tierras que quitaron a sus pobladores. Esta situación cambio con la presencia de Cortés y sus tropas, quienes se consolidaron el territorio a base de batallas con los pueblos, para que se rindieran ante él.

Se ha leído que la población durante la colonia basaba su poder en actividades agrícolas, ya que fue el primer lugar de la Nueva España donde españoles se dedicaron a la agricultura enriquecida por producción de cultivos europeos y productos. Derivado de ello se fabricó harina, enviada a Puebla y México, así como internacionalmente a España y Filipinas, y alrededor de 1567 se otorgan sitios para molinos. En 1775 se conoce gran actividad para el comercio de trigo; "lo que le da fama como el granero de la Nueva España" (Cordoba, D.A. y Mauleón, R.G., 2007).

En 1574 gracias al orgullo de Alonso Díaz de Carrión y sus habitantes por el clima excepcional, grandes vistas de paisajes, campos fértiles y ambiente de costumbres; solicitaron al Virrey el título de Villa, el cual se concede llamándola "Villa de Carrión", con cedula real expedida en Barcelona autorizando la villa y la construcción de la iglesia el 29 de Septiembre de 1579 (Díaz, 1987). Con esto se separó de la Ciudad de Puebla, y pocos años después su riqueza se reflejaría con la edificación de templos y conventos, hospitales y colegios que embellecerían la hoy ciudad.

Durante la siguiente centuria, siglo XVII; se consolidaría la fundación de la Villa, cosechando los frutos del cultivo de trigo y contando con el mayor número de molinos trigueros del país. Al mismo tiempo se establecerían las principales instituciones civiles y eclesiásticas novohispanas, con casas señoriales y templos religiosos que constituían ejemplos del barroco poblano. Para el siguiente siglo hubo crisis económica, no tan severa como en Puebla, pero hubo avance al inaugurar la Real Fábrica del Monopolio de Pólvora aprovechando la zona volcánica, creció la explotación agrícola de haciendas y se expandió el ganado lanar (Córdoba, D.A. y Mauleón, R.G., 2007).

Tras el periodo de independencia hubo trastornos en la vida de la región, debido a que las luchas civiles originaron vandalismo, inseguridad y que la agricultura resintiera, sin embargo al triunfar la guerra se continúa la lógica económica colonial e incrementa la adquisición y arrendamiento de haciendas y ranchos. Posteriormente tras los servicios del "regimiento de Leales de Atlixco" en la independencia, se concede el 14 de febrero de 1843 la categoría de Ciudad, y a los pocos años prestando servicios nuevamente con la invasión Norteamérica de 1847 y la de Francia en 1862; gana el grado de Heroica, título emitido por el Congreso del Estado de Puebla el 28 de noviembre de 1998.

Al finalizar el XIX la ciudad se convirtió en uno de los centros industriales con más apogeo albergando importantes fabricas como el ultimo polo textil de la era porfiriana a nivel nacional (Cordoba, D.A. y Mauleón, R.G., 2007). Como se ha mencionado la importancia de las condiciones climáticas del lugar influyeron de modo tal que la abundancia de sus aguas permitió en principio instalar molinos de trigo en haciendas, que servirían para establecer las fábricas de mayor importancia en la región.

Gracias al apoyo extranjero de inversiones Atlixco incorpora cinco fábricas a las dos existentes con lo cual queda integrado el ramo fabril por: La Concepción, La Carolina, El Volcán, El Carmen con mecanismos hidráulicos y posterior alternación de energía eléctrica, El León por los hermanos Lions, San Agustín y Metepec; últimas que hacia el S.XX traspasarían el mercado local Puebla-Atlixco y tendrían que construir villas aledañas para alojar a sus obreros. Así las haciendas quedarían absorbidas por los ingenios fabriles y posteriormente olvidadas y desaparecidas.

Para finales del siglo XX, y ya con la mayoría de sus fábricas en desuso, y principios del XXI cambia el paisaje con edificaciones modernas que utilizan nuevos materiales como el concreto, y en otros casos las existentes modifican el uso de suelo a museos, hoteles y comercios en general; los conventos y templos se han acoplado a oficinas, y las calles y plazas han perdido la imagen original.

\section{ENTORNO URBANO-ARQUITECTÓNICO DE LA CIUDAD}

\subsection{Traza y características urbanas}

Se hace mención que al ser Atlixco ejemplo de una ciudad española, esta se trazó a partir de una plaza mayor al centro de la ciudad, destinando lugar en este entorno para que cohabitaran los espacios públicos, casas reales, para los personajes públicos, iglesia y portales, punto en el cual convergían las cuatro calles 
principales en ángulo recto, calles que guiarían la expansión de la ciudad a través de la división de manzanas regulares y orientación a los cuatro puntos cardinales; aprovechando el asoleamiento y vientos de la región (Obregón, 1981)

Tampoco se pasó por alto que fuera una ciudad trazada sobre terreno plano y no poblado por indígenas, bastantes pastos y árboles, muchas y buenas aguas, así como pueblos indígenas cercanos para predicar y ocupar en actividades agrícolas de la región. Justamente en el lado donde se edifica la parroquia se levantó la primera casa de gobierno que tuvo la ciudad, como se observa en el plano de Made, hoy ubicada y modificada en el Portal Morelos No. 7, conocida como "Casa de la Audiencia".

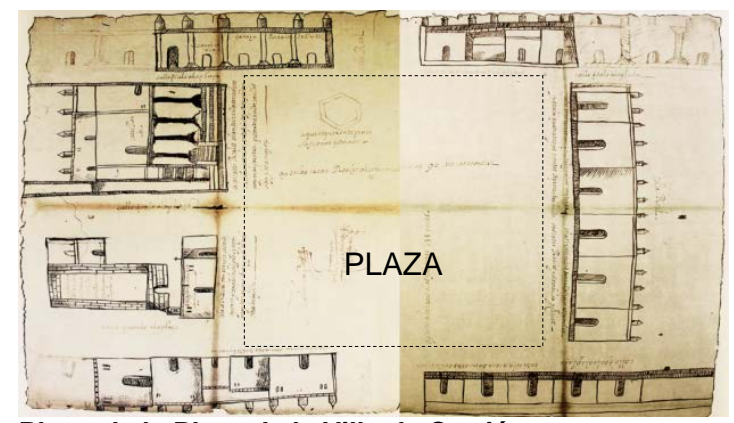

Plano de la Plaza de la Villa de Carrión (Made de Angulo, 1988)

Tales condiciones permitieron, y permiten, que el crecimiento de la ciudad y alrededores conserven un orden y jerarquía de acuerdo a las actividades productivas y comerciales que se han ido adoptando en la ciudad, aspectos que impactan la forma de vivir la ciudad y relacionar sus aspectos cotidianos y sociales con las construcciones y el espacio que habitan. Esta diversidad urbana que se presenta en el territorio ha sido lograda a través de un largo y continuo proceso histórico en el cual la ciudad ha logrado una conformación geográfica y morfología arquitectónica característica (Licona, 2007).

Dicha conformación que al día de hoy ha logrado empatar los caracteres urbanos y arquitectónicos en un conjunto armonioso de paisajes y vistas que permiten que los habitantes llevar a cabo manifestaciones culturales en espacios llenos de historia, y que diversos grupos sociales no permiten que se pierdan. Más bien ante ello y las nuevas generaciones, escasas de su conocimiento, tratan de exaltar las formas simbólicas que dan significado al espacio que apropian.

\subsection{La conformación de la arquitectura}

La conformación de este territorio surgido en torno a las necesidades de los dos grupos establecidos, por un lado el indígena: Acapetlahuacan en torno al convento en la parte alta con calles que esquivan las protuberancias del suelo; y el de españoles: Villa de Carrión en toda la parte baja y plana del terreno dio origen a una intensa actividad de construcción, sobre todo durante la colonia; en la que participaron órdenes y congregaciones religiosas llegadas al territorio.

Tenemos así la primera ermita concebida como primer testimonio material de devoción dedicada a San Félix Papa quien sería elegido como protector de las cosechas, tuvo una primera edificación hacia 1580, la cual hasta 1614 se convertiría en una capilla formal. Posteriormente las congregaciones que arribaron tenían la idea de extender la religión católica y por lo tanto establecer provincias, es así como llegaron los primeros misioneros franciscanos a Acapetlahuacan a mediados del siglo XVI edificando el convento franciscano siendo este la primera edificación española en el valle, cuyo custodio Fray Toribio de Motolinía otorga el nombre de "Val de Cristo" a la región pues la consideraba, por sus atributos, un paraíso.

Esta orden franciscana se encarga también de construir una capilla de la tercera orden en las faldas del mismo convento, obra a la cual siguió surgida como ermita la capilla de San Miguel, espacio consagrado a la devoción del arcángel San Miguel en lo alto del cerro del mismo nombre durante el siglo XVI y que para mediados del XVIII se convertiría en capilla como hoy la conocemos, perteneciente al clero regular.

Los frailes carmelitas iniciaron como ermitaños y se establecieron en la ciudad como la segunda orden regular hacia 1589, dejando testigo en el convento y templo que aun percibimos. Más tarde la orden Agustina fundó su convento en 1590, a los cuales sucedieron los mercedarios fundando convento en 1612, haciendo uso de una zona con casas deterioradas que les fue destinada (Cordoba, D.A. y Mauleón, R.G., 2007). Por otro lado 
la orden hospitalaria de los Juaninos se estableció debido a la importancia social y económica de la región, atendiendo a viajeros y población nativa durante epidemias; sin embargo no se conoce la fecha de su llegada ni asentamiento. Por el contrario se conoce que para 1731 se les concede la toma del hospital de la ciudad que posteriormente se trasladaría al actual asentamiento donde erigen su convento terminandolo hasta mediados del siglo XVIII.

La última en llegar a la región fue la orden femenina de los Franciscanos, nombrada de las damas pobres o Hermanas Clarisas fundando templo y monasterio en 1618, y concluyendo su obra en 1634. Aparte consideraremos el tema de la parroquia principal la cual está dedicada a la Natividad de Nuestra Señora (Divina Infantita), pues el lugar donde se encuentra ya desde la traza inicial de la ciudad era contemplado para tal finalidad, su consolidación se da entre 1606 y 1650, sin embargo es una de las construcciones que presenta varias etapas constructivas que culminan en el S.XIX con las ocho capillas laterales, muestra de etapas sociales que han quedado marcadas en su fábrica constructiva.

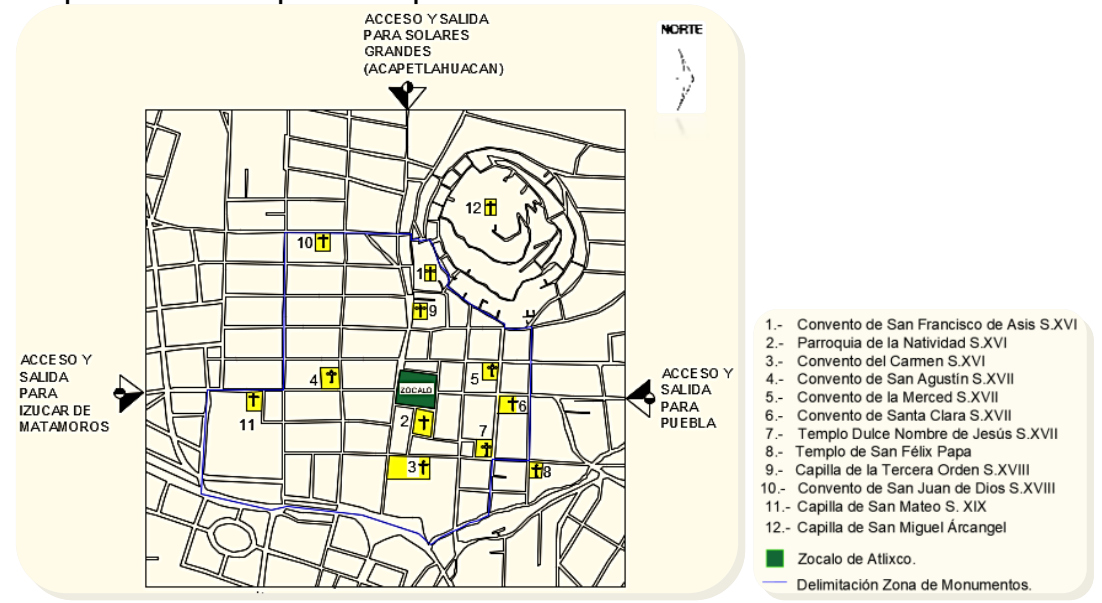

Patrimonio religioso en la cabecera de la Ciudad

(Elaboración propia a partir de datos de campo, 2018)

Con el tiempo la relación entre las distintas órdenes que llegaron contribuiría a un beneficio mutuo, dentro del cual se tendrían que adaptar a nuevos modelos de construcción en beneficio de espacios adecuados para la vida y deberes de la comunidad. Así mismo los frailes fueron los encargados de fungir como arquitectos constructores, aún sin formación pero con habilidad para dirigir la mano de obra indígena (Cordoba, D.A. y Mauleón, R.G., 2007).

En el aspecto civil, las construcciones son diversas y variadas, pues hay ejemplos desde el siglo XVI, en su mayoría perdidos, hasta el XX que muestran elementos simbólicos de cada periodo y que al mismo tiempo se diferencian de los elementos que les fueron añadidos o modificados en diversas etapas constructivas. Sin embargo podemos observar que el material constante a través del tiempo, por lo menos entre el S.XVI y S.XIX, fue el adobe conjugado con otros materiales, como la piedra y el ladrillo, para dar solidez a los muros y losas en las construcciones. Característica que aun en zonas aledañas a la región de estudio no se percibe.

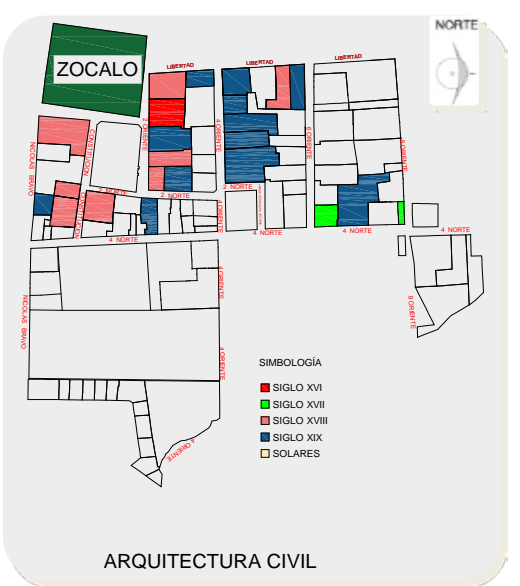

Construcciones civiles por siglo de un sector de la Ciudad de Atlixco (Elaboración propia a partir de datos de campo, 2018) 
El patrimonio edificado aun conservado hasta hoy, tanto religioso como civil ha permitido notarse único e irrepetible, del cual a pesar de haber sido concebido en etapas diversas de desarrollo no dejo de mantener una homogeneidad en el aspecto constructivo, siendo testigos de sistemas constructivos, materiales, diseño y condiciones sociales, culturales y económicas de cada época que las originaron y que al paso de las mismas se vieron transformadas. Las transformaciones se notan ya avanzado el S.XX pues el sistema constructivo y los materiales cambiaron considerablemente, usando el concreto y el acero, con lo cual construcciones antecesoras se intervinieron de mala manera al mezclar estos materiales con los de origen; y como se ha visto aunado esto a aspectos naturales, como los sismos, los edificios no trabajan correctamente y debido a ello mucho del patrimonio de tipo civil se ha perdió irremediablemente.

En la actualidad pocos son los actores que se preocupan por preservar estos inmuebles de valor histórico, cuando se trata de agentes políticos la preocupación recae en inmuebles de aspecto religioso, pero cuando se trata del civil y no corresponde a las autoridades se vuelve más difícil esperar que se conserve. Ante ello parte de la población sigue siendo fiel a no solo conservar sus edificios sino sus paisajes y costumbres, que además de permitir que todo el conjunto de la ciudad siga armonioso, genera recursos que pueden aprovechar para mantener sus inmuebles; esto lleva todavía más a hacer énfasis en reconocer al patrimonio intangible como una herramienta de apoyo al conocimiento y a la economía que permita complementar el patrimonio cultural de la ciudad.

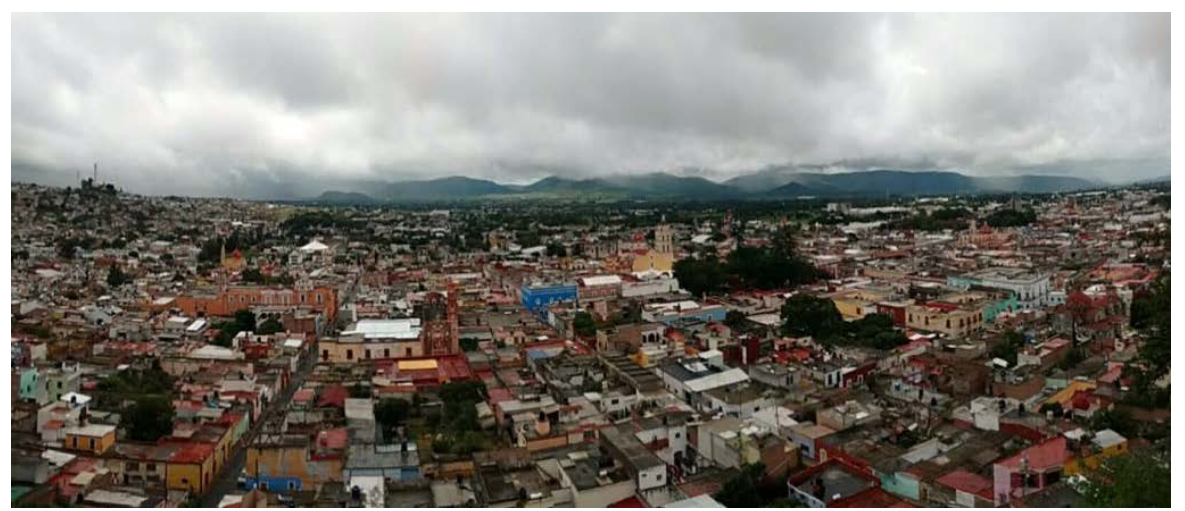

Paisaje urbano-arquitectónico de la ciudad desde el Cerro de San Miguel

(Ruiz, 2017)

\section{APROPIACIÓN SIMBÓLICA DEL ESPACIO URBANO}

A través de una descripción detalla de algunas de las manifestaciones significativas de la sociedad de Atlixco con su entorno urbano construido será posible llegar a establecer la relación entre los diferentes actores sociales y la implicación de salvaguardar el patrimonio intangible que forma parte de la cultura de esta región. Con lo cual se pretende que a través de ello se resalte la importancia de la ciudad como un escenario de interacción, que además de estar dotado de paisajes y edificios, se complementa con la identidad cultural de la población que transforma y diversifica el entorno sobre el que se desarrollan cotidianamente a través de prácticas, costumbres, rituales, itinerarios y rutas, por mencionar algunos ejemplos.

El análisis detalla el proceso de apropiación del contexto en donde se encuentran inmersos los edificios históricos y como las prácticas en torno a los mismos se han convertido en una estrategia discursiva que logra llegar a la conciencia social; a través de la recuperación del pasado para afianzar la imagen que hay en el presente y proyectar a las generaciones un futuro lleno de significado y valores culturales que son apropiados para la conservación de su patrimonio.

En este sentido cuando se habla de patrimonio nos referimos a todo un conjunto de elementos culturales tangibles e intangibles que el hombre hace suyos y utiliza para su desarrollo, en el entendido de que también constituyen una herencia del pasado que está en nuestras para ser conservada y transmitida a futuro. Como se menciona al ser los intangibles parte del patrimonio, y tema de estudio en el presente trabajo, es necesario identificar que hay usos, representaciones, expresiones, costumbres, manifestaciones, música, modos de vida, conocimientos y técnicas, que junto con los objetos y espacios culturales inherentes a los mismos, constituyen la selección individual o colectiva para integrar esté conjunto de intangibles que se manifiestan en un territorio. 
Así, entre la dinámica natural que existe en la comunidad encontramos que no solo seleccionan sino plasman sus manifestaciones sobre un determinado espacio, lo cual implica que este espacio integre su naturaleza y la vida social recíprocamente, donde no se considera estático sino en redefinición constante debido a las prácticas sociales que los diversos actores generan y lo personifican, otorgando en ocasiones nuevos significados; ya que también encontramos una diversidad plasmada en múltiples perspectivas sociales que convergen en un lugar de encuentros de diversa índole, como políticos y económicos.

Al encontrarse diferentes perspectivas de un espacio, se encuentra también que la estructura del mismo se traslada del terreno geográfico a la experiencia individual y social para subjetivarlo según la personalidad, cultura e intereses que se ligan con las experiencias cotidianas, lo cual lleva a generar que los espacios sean apropiados de formas diferentes de acuerdo con las vivencias de cada persona o grupo. Esta apropiación se logra a través de las prácticas generadas en un lugar para adaptarlo a un uso definido previamente o bien redefinido con el tiempo al romper las reglas sociales o simbólicas de dicho lugar. Se aclara entonces que cuando se habla de apropiación, no se hace referencia a la acción literal de enajenar algo y quitarlo sino más bien de identificar los vínculos que las personas son capaces de establecer con los espacios, y como a raíz de esto convergen las ideologías de cada grupo social en una identidad igualitaria que se plasma en un espacio urbano combinando elementos tradicionales y modernos (Tomeu y Enric, 2005).

Esta producción de lo que llamamos identidad la encontramos con la existencia de una forma de identidad relacionada con el espacio apropiado y valorado de acuerdo con su origen y la permanencia de prácticas, lo que lleva a definir una identidad urbana a través del arraigo individual y social con el lugar, en el cual interviene la movilidad, el uso, el conocimiento de las calles y los espacios, y la pertenencia con el territorio; ya que es ahí donde se crean relaciones sociales locales y externas con otras poblaciones. Este aspecto considera que estas relaciones forjan la historia colectiva, debido a la identificación y diferenciación con otros grupos; y permiten una continuidad, integridad y estabilidad de las manifestaciones y la identidad de la sociedad.

Este tipo de identidad permite crear una memoria individual y colectiva como lugar de recuerdos para las prácticas espaciales, que permiten la unión entre los miembros de un grupo social a través de la conciencia social y el arraigo a un territorio, y a la vez permite crear procesos de transmisión de estos conocimientos a otras generaciones. Así encontramos que hay en estos espacios públicos una expresión de la diversidad cultural de la sociedad, que a través de la memoria ha podido identificar manifestaciones dentro de su entorno urbano, y como lo menciona Licona (2007) comparte valores manifestados a través de la vida pública que le proveen de sentido y que crean vínculo con la historia y la cultura común que los distingue.

Todos estos aspectos nos llevan a reconocer que hay en Atlixco prácticas diversas que se han dado desde tiempos atrás, y que siguen luchando y buscando espacios de los cuales hacer uso para manifestarse, y dado que año con año son más numerosas; los espacios requeridos siguen siendo mayores; ejemplo de estas encontramos: 
- El día de los Santos Reyes Magos (06 de enero)

- El día de la candelaria (02 de febrero)

- El día del niño (30 de abril)

- Semana Santa (Abril)

- El día del Trabajo (01 de mayo)

- El día de la Santa Cruz (03 de mayo)

- Invasión Francesa en Atlixco (04 de mayo)

- El día de las Madres (10 de mayo)

- Fiesta patronal de la Divina Infantita (08 de septiembre)

- Festivas del Huey Atlixcayotl (finales de septiembre)

- Día de muertos (02 de noviembre)

- La villa iluminada (Diciembre)

- Además de las fiestas religiosas durante todo el año con el patrono de cada uno de los templos distribuidos en la ciudad.

Esto nos lleva a reconocer que con la riqueza de manifestaciones culturales, no existe una base sólida de información documental material que ampare su difusión y restauración ante la sociedad. Tomando en cuenta este aspecto es que a consideración se retoman tres ejemplos, incluido una de reciente creación, con más convocatoria a nivel local.

\section{SACRALIZACIÓN DEL ESPACIO}

En este sentido el espacio elegido para llevar a cabo estas manifestaciones no ha sido escogido por los habitantes, más bien ha sido descubierto por ellos, pese a que fueron espacios usados con anterioridad para este u otro fin; al tiempo que fueron transformándose y configurándose dentro de los cambios urbanos de la ciudad. Con ello se presentaron ante la sociedad como lugares propios para tales porque constituyen algo diferente.

\subsection{Testimonios religiosos de Semana Santa}

Esta manifestación religiosa se conoce desde tiempos antiguos con la llegada de las órdenes religiosas al valle, quienes celebraban con grandes procesiones que recorrían toda la ciudad para representar la pasión de Cristo, sin embargo después de las Leyes de Reforma de 1857 estas se restringieron a los atrios de los templos (Cordoba, D.A. y Mauleón, R.G., 2007).

La organización para esta celebración recae en la mayordomía de la parroquia de Santa María de la Asunción del antiguo ex convento de San Francisco, quienes se organizan por grupos para adornar la iglesia y las calles, marcar el recorrido por donde pasará la procesión y quienes colocarán los altares de las estaciones, quienes participarán como engrillados y cuál será la banda que acompañará este recorrido. Así se preparan para dar inicio desde el miércoles de ceniza y cada familia todos los viernes hasta el Viernes Santo adorna con alfombras multicolores y símbolos la entrada de sus casas (Cordoba, D.A. y Mauleón, R.G., 2007).Posteriormente ocho días antes de la semana mayor se llevan a cabo los festejos de la Virgen de Dolores, en los cuales se expone la Virgen en los altares de casas y templos, acompañada de adornos de papel picado y símbolos como el cáliz y la hostia. 


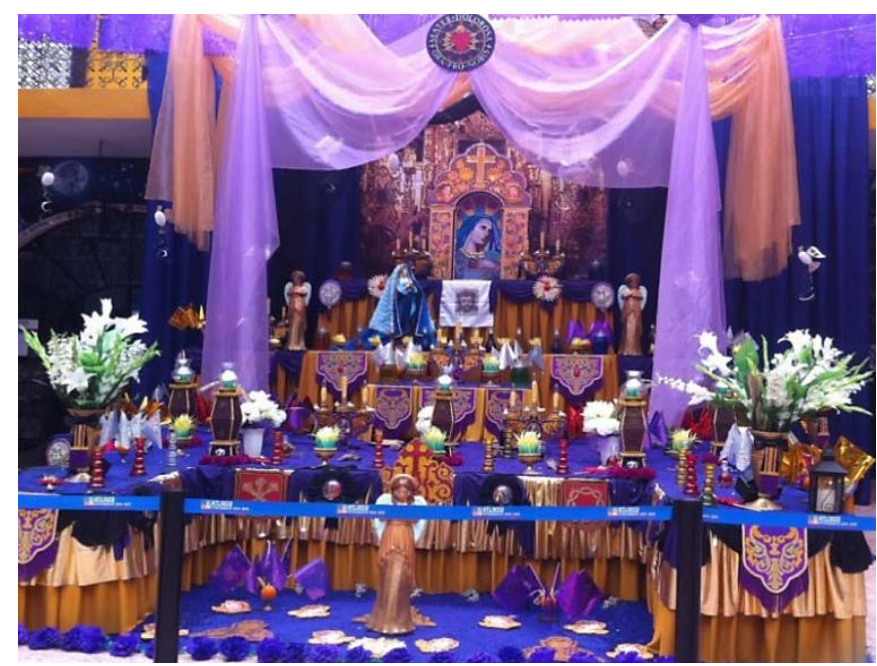

Altar devoto a la Virgen de Dolores del Palacio Municipal realizado por artesanos extranjeros (Flores, 2017)

Para el Domingo de Ramos toda la población católica acude a las iglesias para bendecir sus palmas, mismas que tendrán en sus hogares por el resto del año como protección espiritual. Los actos principales comienzan con el llamado Triduo Pastoral desde el jueves santo por la noche adornando las iglesias y cubriendo los altares e imágenes con lienzos purpuras en señal de luto, las campanas permanecen en silencio y en su lugar se utilizan matracas de madera que anuncian los oficios religiosos. La misma noche del jueves en algunas partes se escenifica la última cena o bien se inicia la dramatización de la pasión de Cristo y se visitan siete iglesias, símbolo de la visita a las siete casas.

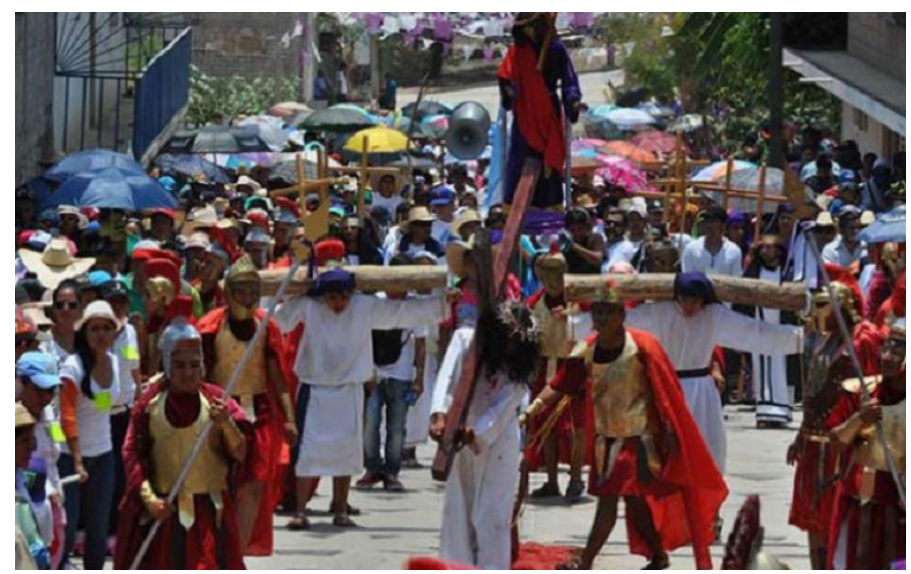

Simbolismo de la pasión en la religiosidad popular urbana

(Flores, 2017)

Posteriormente el Viernes Santo continúa la representación de la pasión al tiempo que se realiza el viacrucis por cada una de las estaciones, poco antes de salir la procesión conocida como "las tres caídas" salen a escena unos seres misteriosos, conocidos antiguamente como penitentes, y que por entrevistas orales se conoce que en la actualidad son llamados engrillados; quienes con cadenas en los pies y manos caminan semidesnudos con un taparrabos obscuro, cabeza y cara cubiertos y una corona de espinas.

Estos personajes cargan cadenas extra sobre sus hombros y son pinchados por tlenchalotes en las partes desnudas, una especie de cactus en forma de alfileteros que van colocando en el cuerpo como parte de la penitencia, además llevan una charola con la cual piden limosnas mismas que serán para pagar sus pecados. Cabe decir que como no tienen visibilidad son asistidos por algún conocido para guiar sus pasos hasta el final del recorrido. Siguiendo a estos inusuales personajes siguen los soldados romanos que hacen avanzar con latigazos al actor que da vida a Cristo, continúan los ladrones Dimas y Gestas y un gran cortejo. 


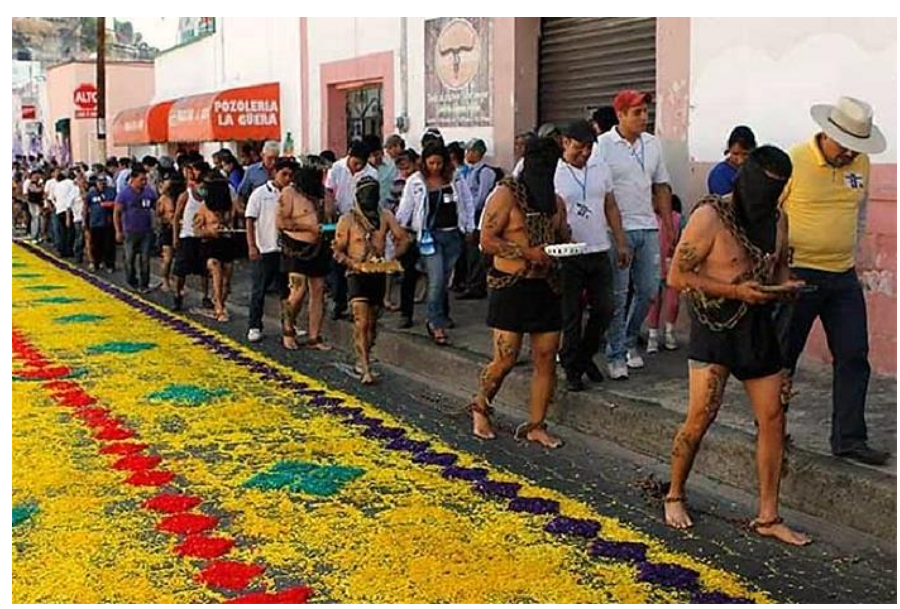

La Ciudad como espacio sagrado para los engrillados

(Flores, 2017)

Particularmente la procesión de la Parroquia es la que reúne más gente y recorre un trayecto más amplio en el cual circulan por cinco colonias aledañas hasta llegar a la portada de la Parroquia en el centro; cabe destacar que aunque el Convento de San Francisco también realiza recorrido no es el mismo ni cruza por los mismos lugares (J. P. Málaga, comunicación personal, 10 de abril de 2017).

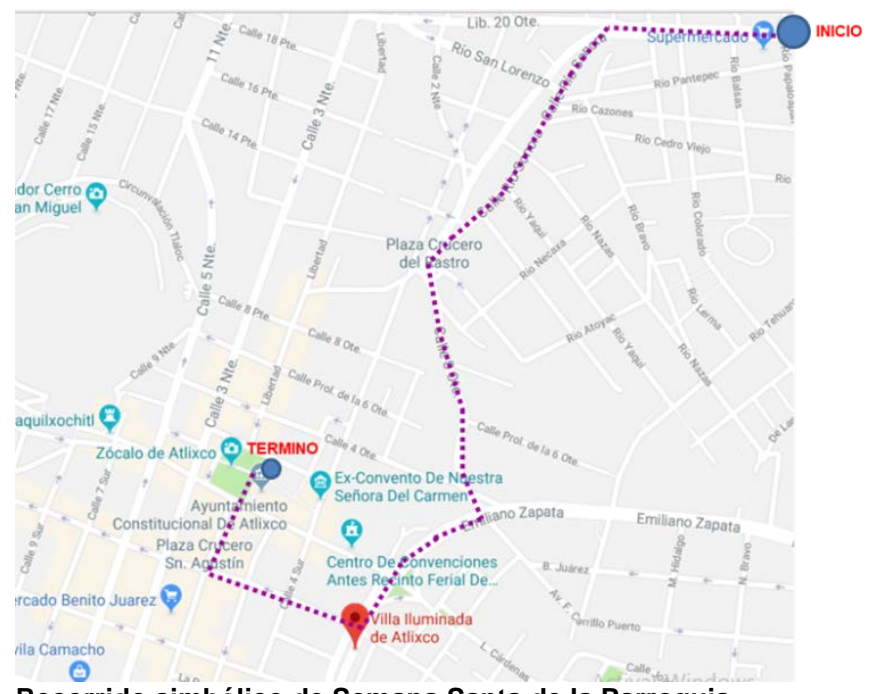

Recorrido simbólico de Semana Santa de la Parroquia

(Elaboración propia a partir de datos de campo y relatos orales, 2018)

Se hace mención que durante la procesión hay cientos de espectadores locales y foráneos que se vuelven participes de la misma y respetuosos de la obra y personajes, mientras recorren las calles adornadas por alfombras monumentales de aserrín de colores y pétalos de flores diversas. Durante este tiempo litúrgico la ciudad vive un sentimiento de luto y tristeza que se ve plasmado en los discursos sociales que sobrepasan el espacio construido e involucran a los actores urbanos en el ambiente simbólico que los lleva a salir a las calles y mostrar su fervor, todo lo contrario buscan sobresalir y que más gente voltee a ver estas costumbres. 


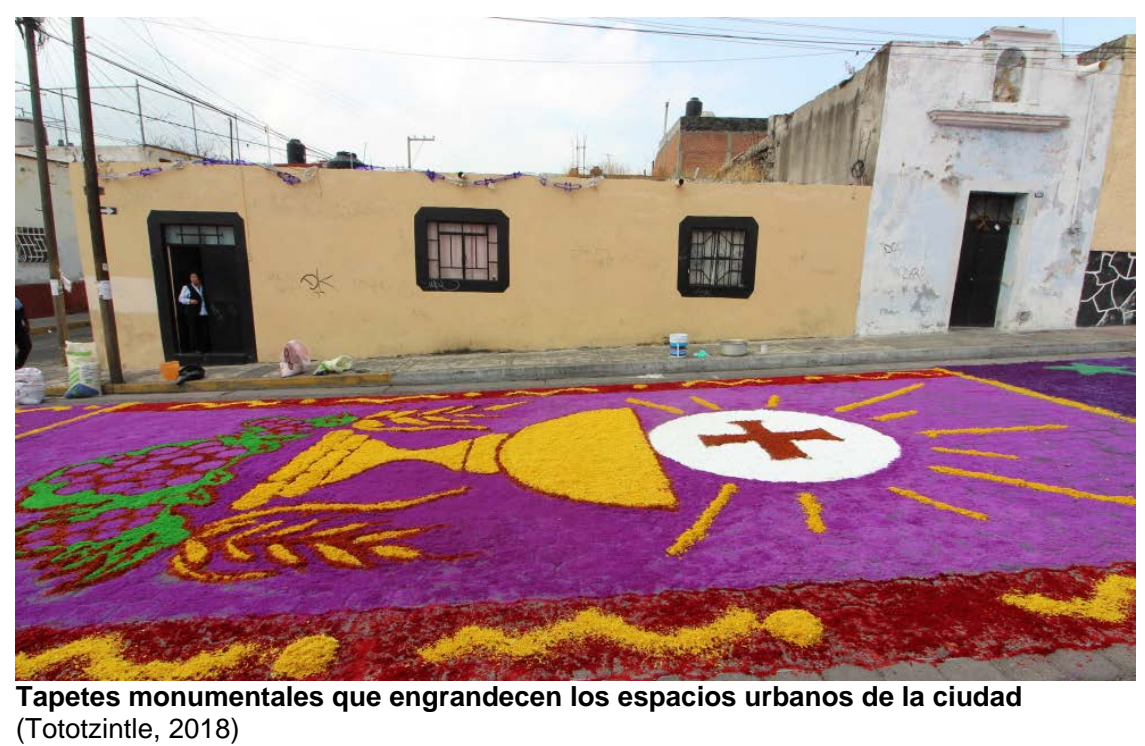

Debido a las características singulares de esta práctica, se ha generado que cada año miles de feligreses asistan a este lugar a ser partícipes y que ello propicie un dialogo entre las autoridades eclesiásticas y de gobierno para atacar las condicionantes urbano- ambientales y económicas que requiere esta y otras celebraciones, otorgando a los visitantes servicios y actividades para desarrollar, favoreciendo el conocimiento de otras áreas de la ciudad.

Sin duda la configuración del espacio externo cambia cuando las prácticas que cotidianamente se dan al interior de los templos salen a buscar puntos que se adecuen a sus visiones, dejando huella y ejemplo para que las generaciones posteriores sigan con estos usos.

\subsection{Configuración simbólica del Huey Atlixcayotl}

Hay procesos que van allá de la propia costumbre, ligados a los ancestros del lugar que se conforman en la memoria y se siguen reproduciendo, incluso cuando se han perdido por completo pequeños grupos que pasan desapercibidos intentan continuar el legado y que no se pierdan estas prácticas; tal es el caso de la fiesta del Huey Atlixcáyotl. Fiesta de naturaleza mística representativa de Atlixco realizada en el Cerro de San Miguel, lugar que por tradición como en otras regiones mesoamericanas, rendía culto al cerro como montaña y donde era venerado el dios Tláloc dador de lluvia para las cosechas o disipador de granizadas. Lugar que posteriormente los pueblos toltecas-chichimecas usarían para venerar a Quetzalcóatl, cambiando su naturaleza en el periodo colonial, donde esta deidad se sustituiría por la de conquistadores; en este caso el Arcángel San Miguel, asociándolo por el viento, el cielo y las plumas como elemento iconográfico (Calleros, B.G., González, B.O.L. y Reyes, P. A., 2015).

Para esta fiesta se destaca la labor del antropólogo norteamericano Raymond Stage Noel, conocido como "Cayuqui" quien llego a fortalecer al pequeño grupo de atlixquenses que buscaban revalorizar y difundir las tradiciones casi olvidadas, grupo que le permitió integrarse a sus núcleos familiares, momento en el cual comienza a registrar todo tipo de acontecimiento social como bodas y bautizos, los cuales llegaban a acompañarse de melodías tristes o alegres según la ocasión. Así es como para 1965 Cayuqui pide concesión al entonces presidente municipal de representar algunas danzas registradas con el fin de darlas a conocer a un grupo de turistas norteamericanos que llegarían de visita, concediéndole permiso el 20 de diciembre para representar un cuento folclórico en la escalera ancha. Ante tal acontecimiento que rompería con la cotidianeidad del lugar debido al desborde de alegría y gusto por la población, y aunque nunca llegaron turistas, comenzaría aquí lo que llegaría a ser una gran fiesta en años posteriores (Calleros, B.G., González, B.O.L. y Reyes, P. A., 2015). 


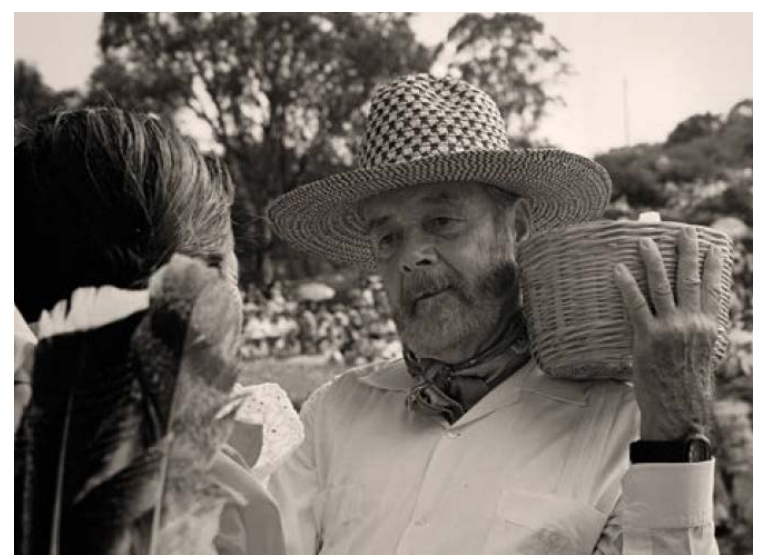

"Cayuqui", figura que destaca el Atlixcayotl

(Parra y Broca, 2007)

Para el año de 1966 siendo ya otro el presidente de la ciudad, este pediría entrevista con Cayuqui para poner a consideración la celebración en el Cerro de San Miguel con el fin de albergar a más asistentes y contemplar la construcción de una gran explanada en la cima aprovechando los cortes naturales del mismo para crear un camino de subida. Nadie imaginaria que este sería el lugar más adecuado para tal festividad, verdaderamente fue este el momento en el que inicia la historia con el apoyo de dos grandes fuerzas como lo era el pueblo, el antropólogo y la unidad administrativa que encaminaría las obras a una mayor trascendencia cultural.

Es así como la tradición se lleva acabo a cabo año con año el segundo o tercer domingo de septiembre en el cerro o lugar del Atlixcayotontli o fiesta de la región de Atlixco con la participación de toda una ciudad unida. Celebración que resulta de la interacción directa que existe entre diversos grupos indígenas y mestizos de varios puntos de la región poblana que se unen para recrear el origen de este ritual ancestral a través de la danza, el canto, la poesía y la música; hoy se conoce que además de la región cada año hay un estado invitado a compartir sus costumbres con el pueblo local, lo cual ayuda a contribuir con la diversidad cultural a nivel nacional.

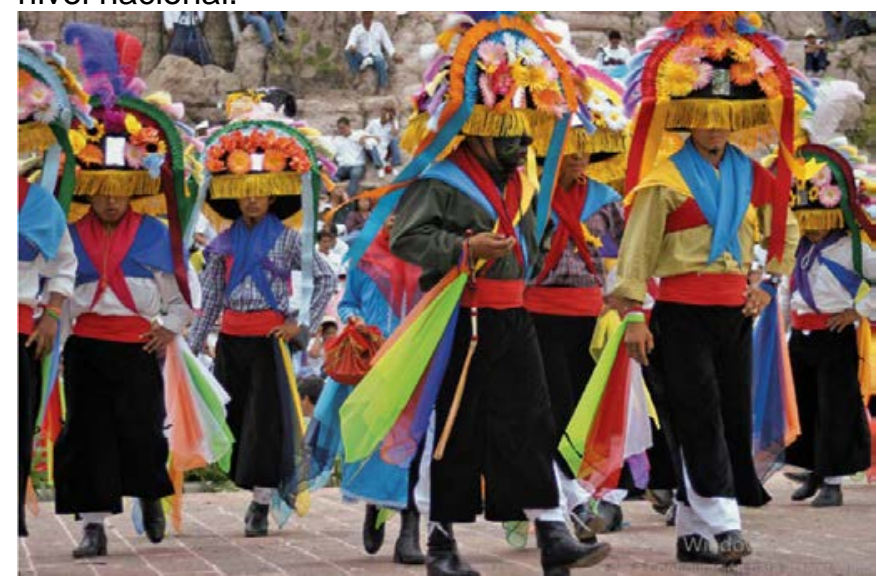

Danza de Negritos, un colorido esencial (Parra y Broca, 2007)

La fiesta inicia con la "llamada", conocida como "convite" dos semanas antes, recorriendo junto con los organizadores la gente del lugar, calles principales de la ciudad y haciendo parada en las iglesias del centro para bailar el tlaxcalteco que con el huehuetl, chirimía y tarola aluden con sonidos a la tradición invitando a los atlixquenses a la festividad. 


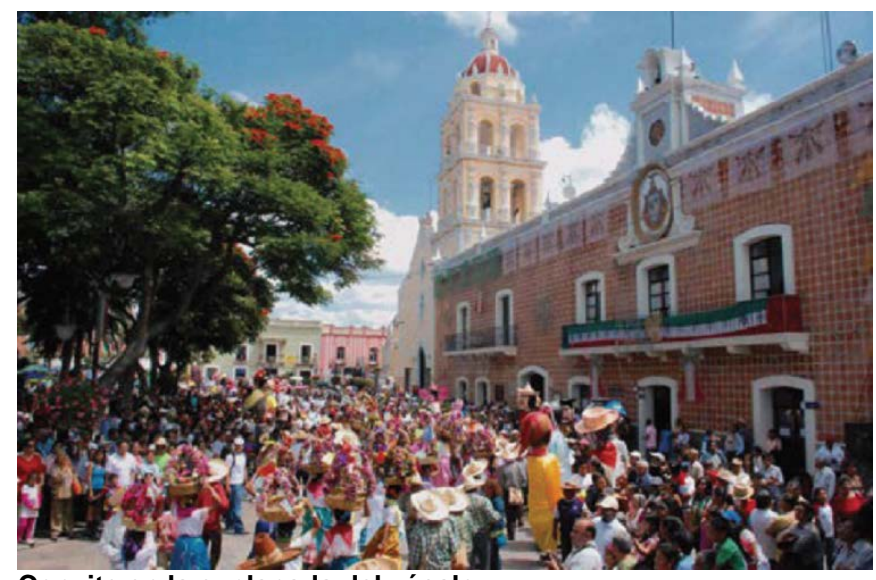

Convite en la explanada del zócalo

(Guzmán, 2014)

Posteriormente ya en la celebración en el Netotiloyan (cerro) se ofrece al joven Macuixochitl "cinco flor" dios de la juventud, alegría, danza y música. Ahí mismo se entrega el topilli "nuestro bastón", de madera y grabados alusivos con un listón por año celebrado, que porta autoridad para presidir el festival y junto con el la xochicihuatl "mujer flor" elegida una noche anterior de entre las comunidades participantes como símbolo de la mujer indígena, cabeza y pie de familia con valores de pureza, conocimiento de lengua materna y dones de la región (Calleros, B.G., González, B.O.L. y Reyes, P. A., 2015).

Con el topilli se autoriza el corte del listón en el arco de cucharilla, justo a la entrada de la explanada frente a la Capilla de San Miguel; por ahí entrarán las chinas atlixquenses y charros que simbolizan a los atlixquenses como anfitriones. Se abre la fiesta con una danza donde participan anfitriones e invitados cargando un guajolote, pulque y tortillas, lo que indica que no faltará ni comida ni bebida. Así los visitantes se preparan para apreciar a cada una de las comitivas y sus mejores expresiones social, artísticas y culturalmente hablando; indígenas, mestizos y ahora extranjeros se reúnen para engrandecer el orgullo de ser y pertenecer a una comunidad que no quiere desaparecer, manifestando su historia en un entorno natural que empata los espacios con sus tradiciones en un presente donde diariamente luchan y subsisten por mejorar su futuro, sin perder estos elementos culturales que han ido forjando a lo largo del tiempo una identidad y memoria colectiva en toda la región.

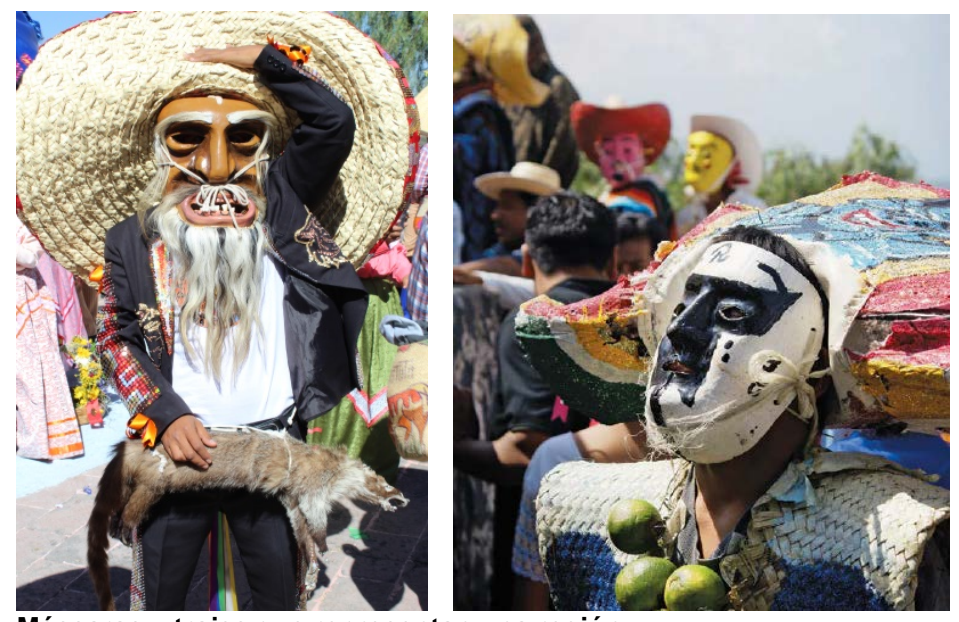

Máscaras y trajes que representan una región

(Ruiz, 2017)

Siendo un proyecto que para su época ya se encontraba en un contexto mundial logro constituirse como una celebración cultural y étnica que muestra la autenticidad de las comunidades y su motivación para que año con año se le diera continuidad, la fiesta quedo inmersa en un ambiente dinámico donde hoy aunque las danzas y música han tenido adaptaciones por la inclusión de la modernidad, el origen sigue siendo vital. Del mismo modo que el contexto mundial influyo para su desarrollo y engrandecimiento, pues era de gran importancia destinar un espacio donde la fiesta se manifestará; así hasta el día de hoy el cerro de San Miguel ha ido configurando diversas formas para dar cabida a estas manifestaciones y en lo posible respuesta a las 
necesidades, sin que ello allá implicado una total destrucción del patrimonio natural que lo envuelve, por el contrario ha encontrado en este tipo de celebraciones un arma para que más visitantes suban a conocer el patrimonio edificado que se encuentra en la cima y contemplar las vistas de la ciudad que desde ese punto podemos apreciar.

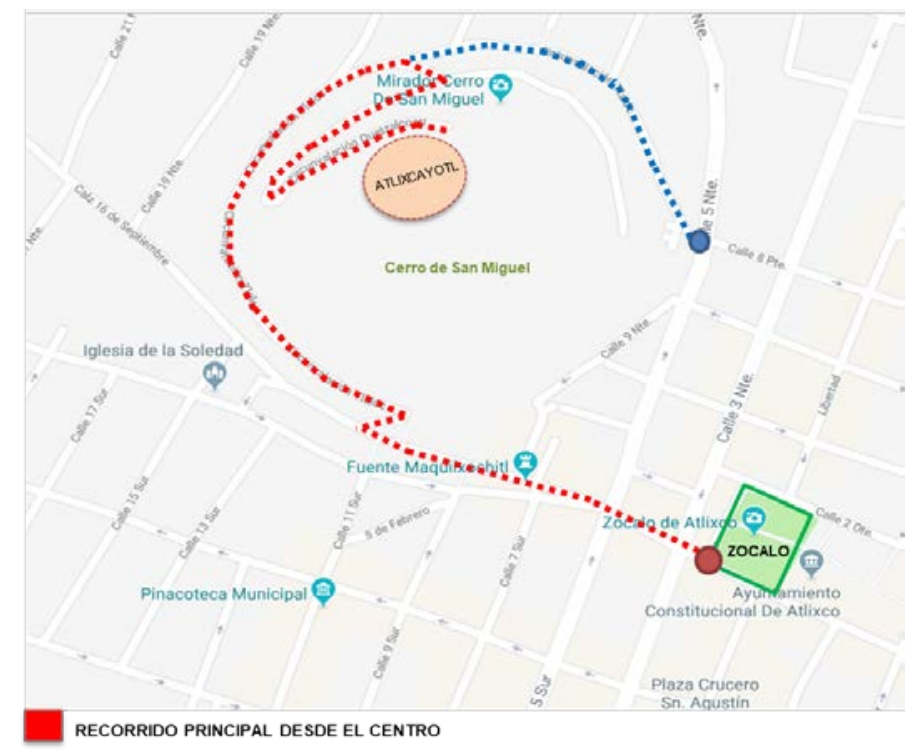

RECORRIDO SECUNDARIO DESDE EL AHUAHUETE

Ubicación y accesos al Cerro de San Miguel respecto al centro de la ciudad

(Elaboración propia a partir de datos de campo y relatos orales, 2018)

Al día de hoy, a través de la fotografía como memoria documental, es posible observar como este espacio dotado de gran naturaleza se ha ido transformando a raíz de una celebración que buscaba espacio para manifestarse, la población en general hoy es capaz de identificar el sitio sin tantas señas, pues surgió como producto de las interacciones de diversos sectores en torno a la realización y demostración de sus tradiciones, que continuamente han transformado el entorno donde se desarrolla, tomando en cuenta las múltiples realidades presentes que lo significan social y territorialmente.
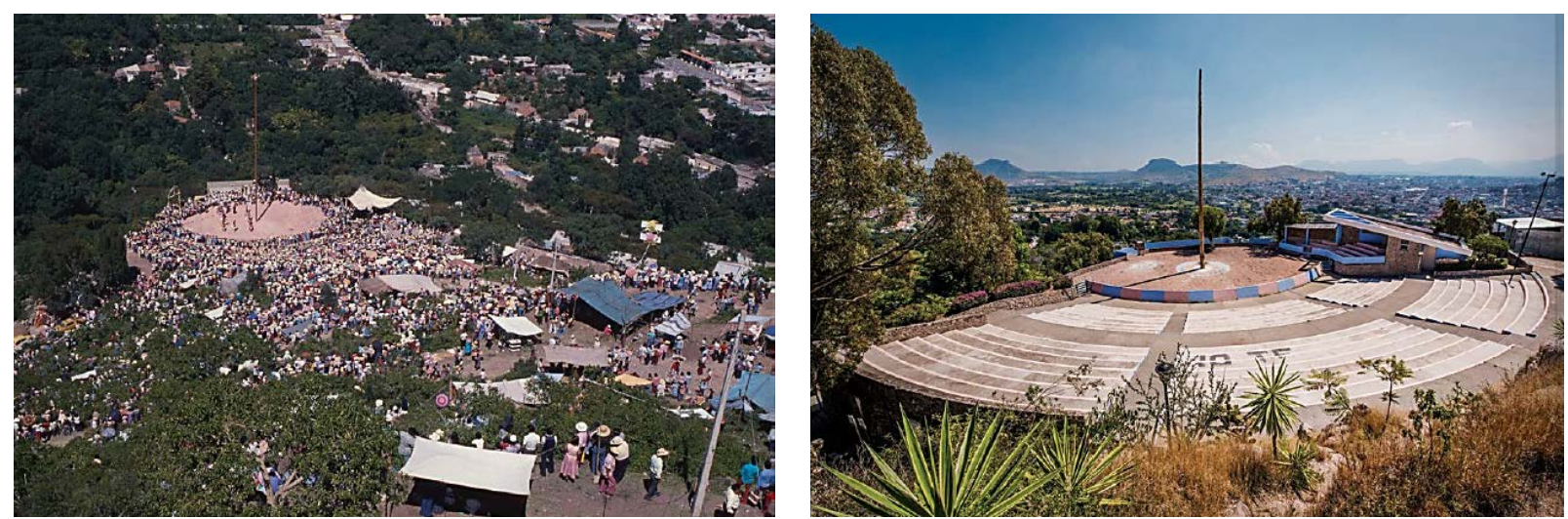

Transformación del espacio tras la apropiación del espacio para la festividad (Paredes, 1979 y O’Leary, 2015)

Este año, característicamente, jugo un papel importante para que dicha celebración se realizara, ya que a raíz del sismo del 19 de septiembre, que dejo rezagos en la ciudad, tanto la capilla en la cima del cerro como parte del entorno se vieron dañados; lo cual impidió que la fiesta se realizará en las fechas cotidianas, para cuidar no solo la integridad de la gente sino la de la edificación que no se encontraba en condiciones para recibir una concentración tan grande de gente, que además de la presencia, bullicio, baile y música repercutirían en el físicamente. Es por ello que se realizó hasta el mes de diciembre, y no por ello dejo de tener una gran afluencia como cada año, constituyendo además de todo una oportunidad para unir a la población que se encontraba en un estado de ánimo cabizbajo, sino también recordar que es un evento que integra sus lazos familiares y afectivos con el patrimonio. 


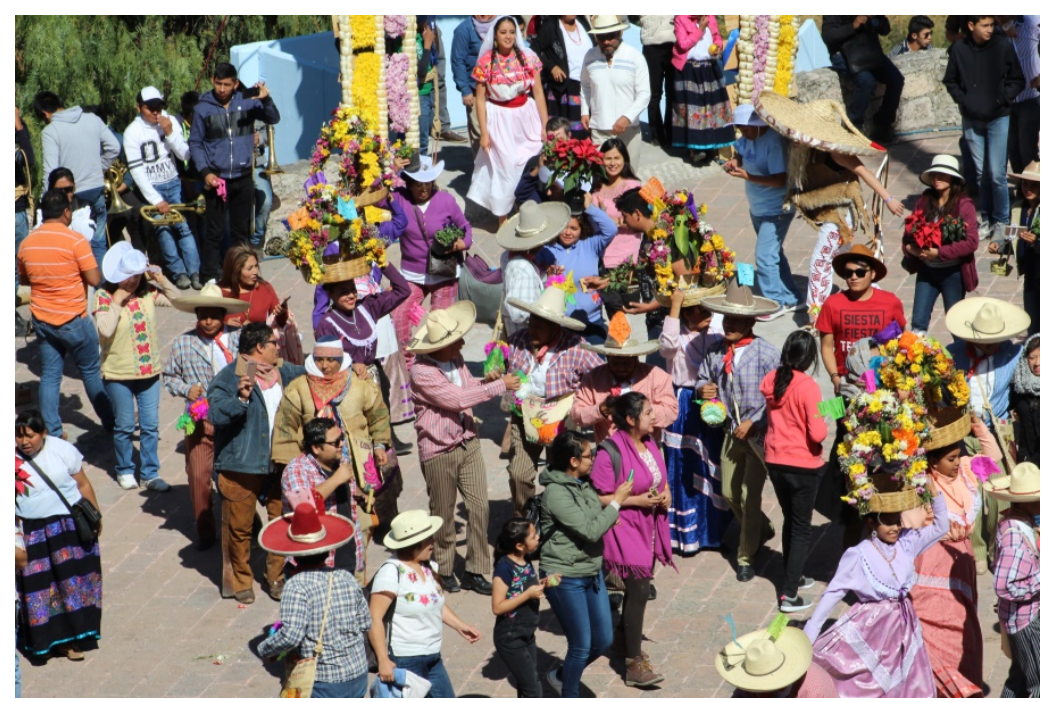

Convivencia de los asistentes en el baile de la región con la población local (Ruiz, 2017)

\subsection{Modernización del espacio con la Villa lluminada}

A sido través de la renovación e inclusión al mundo moderno que esta ciudad ha logrado conservar, preservar y difundir lo que queda de su patrimonio cultural, el caso es que en este proceso algunas expresiones se han visto envueltas en otras más predominantes como es el caso de la Villa lluminada, originada a raíz de ser nombrado Atlixco como Pueblo mágico en el 2015, lo cual implico que adquiriera ciertas influencias en cuanto a las celebraciones arraigadas. Es una celebración que se lleva a cabo en la antigua estación de ferrocarril y vías; que durante el mes de diciembre, lucen a lo largo de más de un kilómetro y medio que culmina en el centro de la ciudad, brillantes luces que adornan la avenida mostrando diversas figuras alusivas a los caracteres de la región. Tal es el caso de las flores, particularmente la noche buena y flor de muerto.

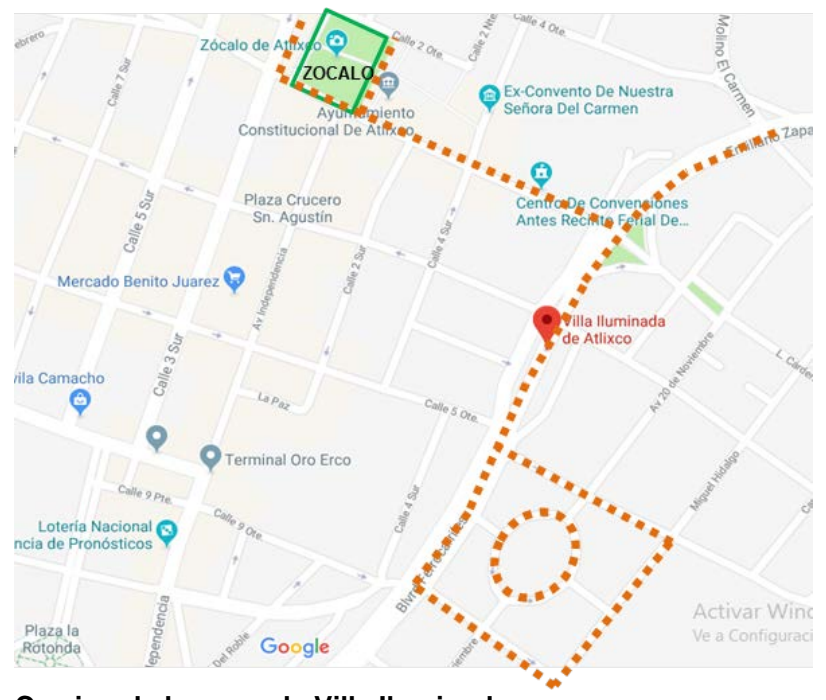

Camino de luces en la Villa lluminada

(Elaboración propia a partir de datos de campo, 2018)

Este espacio que antes ha servido para la interacción de diversos sectores desde su utilidad como estación y hoy como biblioteca y puestos de comida, ha sido objeto de una diversidad social y cultural mediante la vida pública que se ha abocado a él, siendo organizada por el gobierno local y economía turística, constituye actualmente a nivel nacional un obligado referente de visita durante diciembre, cambiando el uso de día a una vista totalmente diferente por la noche, el que permite una convivencia de familias y sectores diversa índole. 


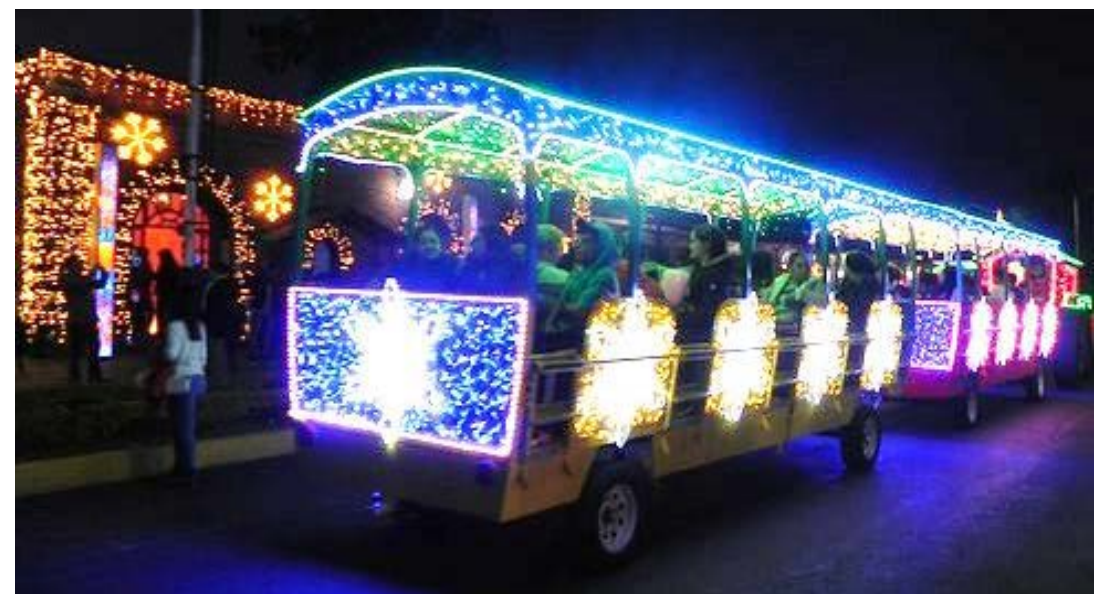

Iluminación de la Antigua estación de Ferrocarril

(Flores, 2017)

Hoy esta imagen que permite identificarse con el patrimonio edificado e inmaterial, permite que como sujetos externos atribuyamos diferentes valores a los objetos, olores, colores y festejos que vemos en un espacio y que dan sentido para generar una carga simbólica que posibilita apreciarlos adecuadamente. En este caso la apropiación del espacio urbano conlleva una transformación total del mismo del día a la noche en el que la relación de actores sociales con el espacio genera una percepción individual capaz de dotar el entorno de diversas formas lo cual le da un carácter especial al espacio público que conforma el paisaje urbano.

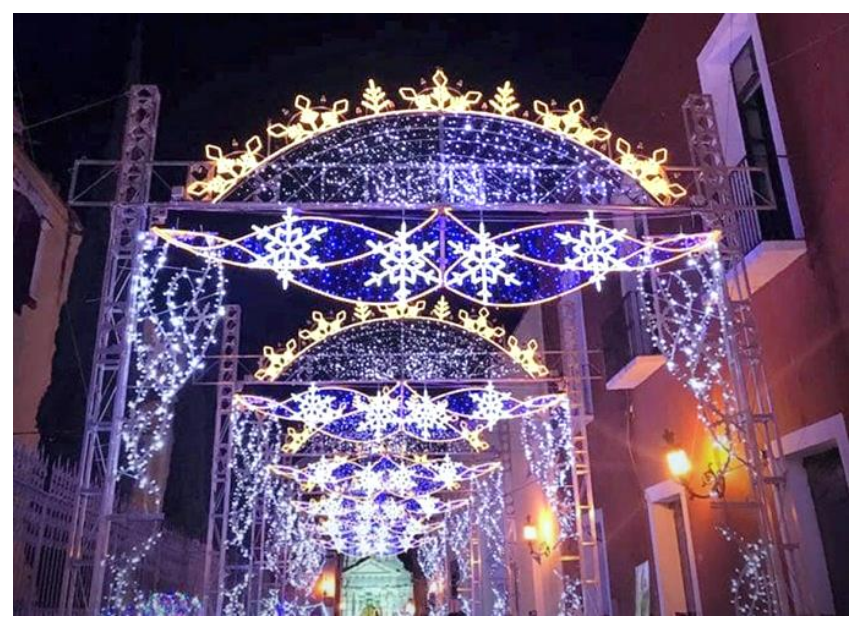

Puente de luces que lleva a la plaza principal (Flores, 2017)

Como se observa está más que una manifestación tradicional se ha convertido en una nueva estrategia de inserción en el mercado económico, pues han implementado una renovación urbana que parte de cierto sector para explotarlo por medio de la integración de la economía local de la ciudad, con las fábricas luminarias, a pesar de ello deja de lado la identidad de la población que ve al espacio transformado; sin embargo a pesar de ello el papel que está jugando la memoria colectiva en las nuevas generaciones se vuelve imprescindible cuando tomamos en cuenta que aunque moderna se está convirtiendo en una práctica que pasará al futuro.

\section{CONCLUSIÓN}

Gracias al estudio de esta región, es que ha sido posible conocer un aspecto que ciertamente no se podría reconocer ni dar valor adecuadamente sin estar en contacto con los espacios y su gente, actualmente se puede hablar de esta ciudad con el conocimiento de sus valores, recursos y elementos del patrimonio con los que cuenta.

De esta característica de sentirnos pertenecientes, recae el estudio del espacio urbano y su transformación a partir de la implicación de sus manifestaciones simbólicas como realidades complejas que son difíciles de estudiar, pues esto conlleva a ver diversos puntos de vista y expresión que modifican la vida social. Así se ve como a través de estos ejemplos, la percepción de la ciudad se modifica notablemente de acuerdo con el 
medio y las practicas generadas en el mismo, puesto que hasta la sociedad se diversifica en cada una de estas manifestaciones, lo cual genera que un espacio sea significado de la acción social y su interpretación individual y colectiva.

Muchas de estas transformaciones en el espacio se han generado por un largo o corto plazo, lo que depende de la forma de ver y generar vínculos con estos espacios, es por esto que se destaca el aspecto intangible en el uso de los espacios simbólicos urbanos, para rescatar y reforzar la identidad social hacia estos espacios y que no pierdan el sentido de su creación, que en este aspecto más allá de volverse un objeto de consumo ante la globalización y alejado de la interacción social local, constituyan un factor integrador de discursos socioculturales que favorezcan la conservación y difusión del patrimonio cultural de Atlixco.

Esto no solo conlleva apropiar un espacio sino entender el espacio para facilitar en él comportamientos sociales y ecológicamente responsables que permitan su valoración a escala urbana y social dentro de la población, lo cual implica que las transformaciones se noten a diversas escalas, como se ha mencionado, pudiendo ser temporales o bien permanentes en constante cambio.

\section{BIBLIOGRAFIA}

CALLEROS, B.G., GONZALEZ, B.O.L. y REYES, P. A. (2015). Atlixcáyotl cincuenta años de cultura y tradición. México: Reproducciones Gráficas Avanzadas.

CORDOBA, D.A. y MAULEON, R.G. (2007). Atlixco Historia Patrimonio y Sociedad. Atlixco. Puebla: L'Anxaneta Ediciones S.A. de C.V.

DÍAZ, M. (1987). Antigua Villa de Carrión. Arquitectura religiosa y civil. Puebla, México: Centro Regional Puebla, Inah.

LICONA, V. E. (2007). Habitar y significar la ciudad. México: CONACYT-UAM.

MEADE, DE A. M. (1988). Cartografía de Atlixco 1578-1854. México: Artes gráficas S.A.

OBREGÓN, G. (1981). Atlixco La ciudad y sus monumentos. México, D.F: Departamento de Impresiones INAH.

TOMEU, V. M. y ENRIC, P. U. (2005). La apropiación del espacio: una propuesta teórica para comprender la vinculación entre las personas y los lugares. Anuario de Psicología (Barcelona), 3, 281-297. 